\title{
Deploying temporary networks for upscaling of sparse network stations
} Evan J. Coopersmith ${ }^{1}$, Michael H. Cosh ${ }^{1}$, Jesse E. Bell ${ }^{2,5}$, Victoria Kelly ${ }^{3}$, Mark Hall ${ }^{4}$, Michael A. Palecki ${ }^{5}$, and Marouane Temimi ${ }^{6,7}$

${ }^{1}$ USDA-ARS-Hydrology and Remote Sensing Laboratory, Beltsville, MD 20705

${ }^{2}$ Cooperative Institute for Climate and Satellites - NC - Asheville, NC 28801

${ }^{3}$ Cary Institute of Ecosystem Studies - Millbrook, NY 12545

${ }^{4}$ NOAA-ATDD/Oak Ridge Associated University, Oak Ridge TN

${ }^{5}$ NOAA's National Centers for Environmental Information - Asheville, NC 28801

${ }^{6}$ City College of New York, New York, NY

${ }^{7}$ Masdar Institute of Science and Technology, UAE

\begin{abstract}
Soil observations networks at the national scale play an integral role in hydrologic modeling, drought assessment, agricultural decision support, and our ability to understand climate change. Understanding soil moisture variability is necessary to apply these measurements to model calibration, business and consumer applications, or even human health issues. The installation of soil moisture sensors as sparse, national networks is necessitated by limited financial resources. However, this results in the incomplete sampling of the local heterogeneity of soil type, vegetation cover, topography, and the fine spatial distribution of precipitation events. To this end, temporary networks can be installed in the areas surrounding a permanent installation within a sparse network. The temporary networks deployed in this study provide a more representative average at the 3$\mathrm{km}$ and 9-km scales, localized about the permanent gauge. The value of such temporary networks is demonstrated at test sites in Millbrook, New York and Crossville, Tennessee. The capacity of a single U.S. Climate Reference Network (USCRN) sensor set to approximate the average of a temporary network at the $3 \mathrm{~km}$ and $9 \mathrm{~km}$ scales using a simple linear scaling function is tested. The capacity of a temporary network to provide reliable estimates with diminishing numbers of sensors, the temporal stability of those networks,
\end{abstract}


and ultimately, the relationship of the variability of those networks to soil moisture conditions at the permanent sensor are investigated. In this manner, this work demonstrates the single-season installation of a temporary network as a mechanism to characterize the soil moisture variability at a permanent gauge within a sparse network.

\section{Introduction}

National soil-observation networks offer a valuable mechanism for understanding belowground climate change by providing a critical scientific data record (Schaefer et al. 2007; Bell et al. 2013). Data from these networks can be used for understanding drought, calibration of land surface models, validation of remotely sensed soil moisture, and even topics related to human health (Beck et al., 2000). Understanding changes in soil moisture dynamics gained national attention with the historic 2012 drought in the United States (Bell et al., 2015; Blunden and Arndt, 2013) and recent outbreaks of coccidioidomycosis (Valley Fever) that are shown to be related to changes in soil moisture (Stacy et al., 2012). However, knowledge of soil moisture variability is still incomplete (Ochsner et al., 2013; Palecki and Bell, 2013). Further research is still required to understanding how effectively a single station represents its surrounding area, as in situ measurements of soil moisture are often too sparse to fully characterize soil dynamics at broader spatial scales (Cosh et al., 2013). Given the considerable importance of these measurements for droughtmonitoring, agricultural yield estimation, and ground validation of soil moisture from satellite and land-surface models, research characterizing the representativeness of a single station to its surrounding area is critical for maximizing the value of soil moisture measurements from any network collecting data (Kornelsen et al. 2015). 
Soil monitoring networks are expensive to operate and difficult to maintain (Schaefer et al. 2007; Bell et al. 2013; Temimi et al, 2014). Any effort to provide national, high-density soil moisture monitoring is too costly and time intensive to be sustainable. Efforts are being made to assemble existing soil monitoring network data into larger databases with uniform quality control procedures (Dorigo et al. 2011, 2013; Quiring et al., 2016), and apply spatial interpolation techniques (Ford and Quiring, 2014). There is also growing interest in ingesting soil moisture observations into weather and climate models that normally depend on modelled soil moisture inputs (Dirmeyer et al., 2016). However, soil moisture is highly variable and a dense network of stations is required to accurately characterize spatial variability (Magagi et al., 2013). In order to reduce cost and improve spatial coverage, previous studies have been conducted to temporarily deploy a higher density network to determine a scaling function for that network (Cosh et al., 2006; Cosh et al., 2013; Scaini et al., 2015). By identifying the scaling relationship of a station to the larger domain, researchers and land managers may be able to use measurements of soil moisture from sparse data networks more accurately for a variety of scientific and societal needs. However, none of those studies were focused on singular permanent stations. Before this relationship is established, work needs to be done on understanding the limitation and similarities of soil moisture variability at different geographic locations and soil types. By characterizing the spatial soil moisture variability surrounding locations, it may be possible to apply a scaling strategy to all stations (Vachaud et al., 1985; Crow et al., 2012; Cosh et al., 2013). This scaling strategy can then be deployed to generalize the relationship of soil moisture measurements from a single point to the larger domain. 
To characterize the representativeness of a single station to its surrounding area, installations of temporary networks of stations monitoring soil moisture were deployed to evaluate the spatial variability surrounding two permanent stations in a sparse national network. By instrumenting a variety of landscapes near each station, we will be able to identify the spatial representativeness of individual stations and determine the limitations of scaling a single station to a larger domain. This work will serve as a platform for improving the utility of sparse data networks. As NASA's Soil Moisture Active Passive (SMAP) satellite mission (Chan et al. submitted) was recently launched, this work will be able to directly contribute to better calibration/validation of the satellite's soil moisture measurements with sparse data networks. The outcome of this pilot project is to develop 1) a better understanding of spatial representativeness of a common station to the surrounding area, 2) a scaling strategy that can be used for the life of any permanent soil observing station, 3) an improved metric for scaling any single point measurement to the surrounding area, and 4) an improved methodology for using scaling individual point soil moisture measurements for calibration/validation of larger-scale, remotely-sensed and modeled soil moisture data products.

\section{Test Sites and Data Collection Methods}

NOAA's US Climate Reference Network (USCRN) is a sparse data network that records a variety of homogenous above- and below-ground climate data (Bell et al. 2013). USCRN stations normally have soil-monitoring probes at five depths: $5 \mathrm{~cm}$ (the focus of this study), $10 \mathrm{~cm}, 20 \mathrm{~cm}, 50 \mathrm{~cm}$, and $100 \mathrm{~cm}$. Soil probes are installed in three plots around the station tower; the triple redundancy of measurements at each depth aids quality control and allows for a continuous data record. USCRN locations are evenly distributed across the United 
States and generally located in remote areas that are stable with respect to human development (Diamond et al. 2013). Because of the placement of USCRN gauges, each station is located in areas with topography, landscape, and soil types that may or may not differ substantially from their surroundings. As a consequence, spatial variability in the surrounding area can be challenging to characterize. The two stations selected for this pilot study were near Crossville, Tennessee and Millbrook, New York (Temimi et al, 2014). Station positions were selected with consideration towards representing the diversity of soil textures and topographies present within the watershed, maintaining an appropriate spatial distribution, and minimizing inconvenience to the local landowners who allow installation of these gauges on private property. 

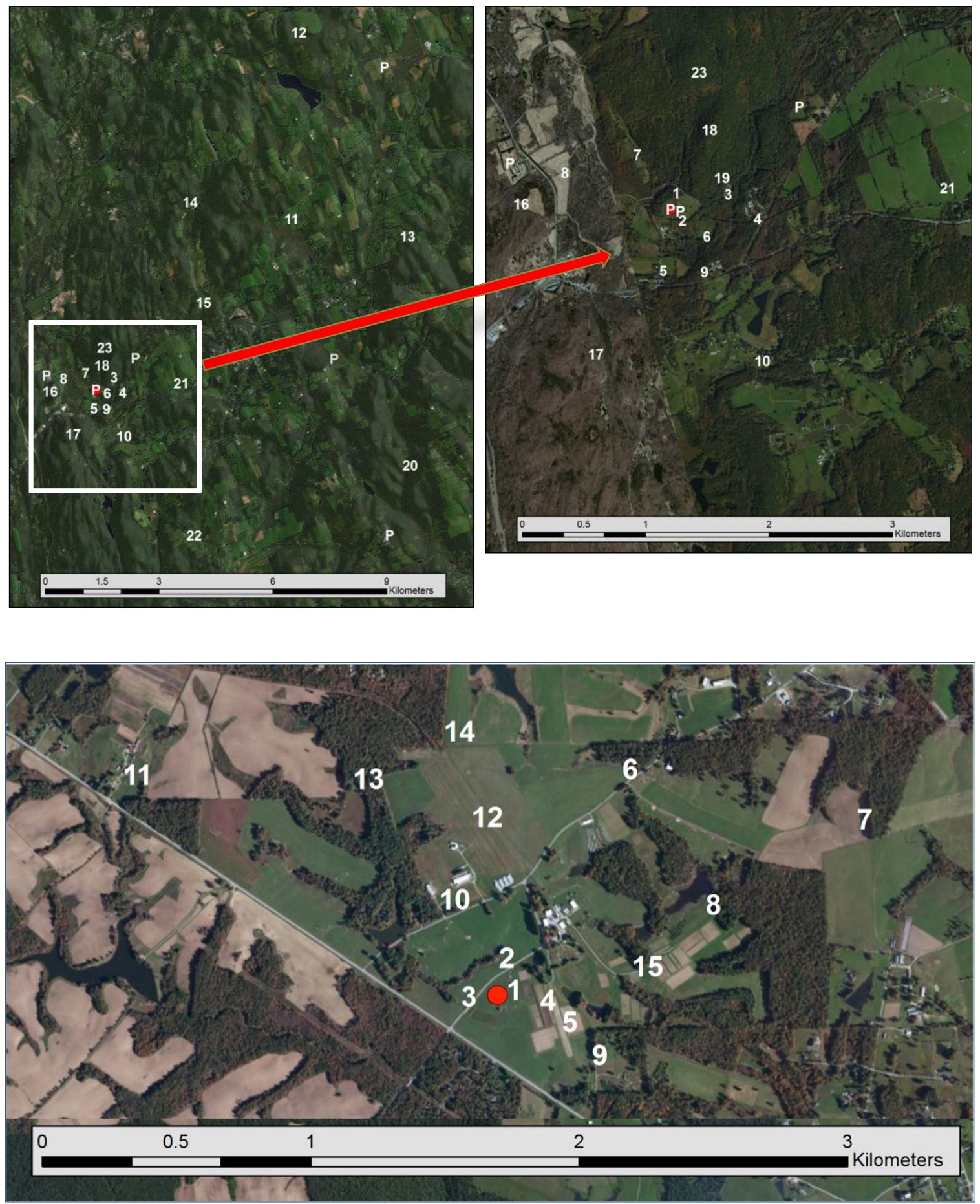

Figure 1 -Design of the network of temporary stations installed around the USCRN station at Millbrook, NY (top) and Crossville, TN (bottom). 
The Millbrook USCRN station is located at the Cary Institute for Ecosystems Studies, while the stations of the temporary networks were installed across the land parcels of a variety of landowners in the surrounding area (Figure 1, top). The installation of the temporary network at Millbrook lay across a variety of diverse locations and topography; including fields, pastures, and wooded areas. At each temporary installation, the top layer of soil was carefully removed for the insertion of a Stevens Hydra Probe into the vertical soil profile at $5 \mathrm{~cm}$ depth to replicate the USCRN installation (which is intended to estimate soil moisture at the $5 \mathrm{~cm}$ depth) and to represent the soil moisture depth of the NASA SMAP mission. The removed soil is replaced around the probe to fill the hole and cover the exposed probe. The top layer of soil that contains the aboveground biomass is placed over the hole and compacted to remove air pockets. Twenty-five temporary stations were installed in a random pattern around the USCRN station. The design of the temporary network allows for an examination of a 9-km SMAP satellite product, intended to estimate soil moisture at the $5 \mathrm{~cm}$ depth. The layout also provides an opportunity for the temporary network to be divided into 16 stations that can represent the 3-km SMAP product (also intended to provide a $5 \mathrm{~cm}$-depth estimate). Soil cores and gravimetric soil samples were extracted near the probe. Samples were brought back to the lab for drying and analysis of soil type, bulk density and gravimetric soil moisture. Near the temporary probe installation sites, a metal fence post is driven into the ground and the data-logger box and solar panel are attached. Periodically, the sites were visited for visual inspection, downloading data, and gathering the requisite gravimetric soil samples for calibration. Downloaded soil moisture observations were then processed and inspected for quality assurance. 


\section{Analytical Methods}

Five primary approaches were deployed to assess the spatial robustness and temporal variability of the temporary networks as they related to the permanent network sites. This section will outline the techniques used and the insights to be gained that are applicable to understanding sparse network representativeness.

\section{Temporal Stability Analysis}

In this analysis, the relative conditions of soil moisture at the temporary network sensors and at the permanently-installed USCRN station are compared. In a temporally-stable network, one expects specific sensors to remain among the wettest in the network, regardless of conditions, while others remain among the driest. For each sensor, a normalized soil moisture time-series is obtained by subtracting the mean soil moisture value over all temporal network sensors from each individual sensor's time series. By calculating the mean and standard deviation at each temporary network location, the meanrelative-difference (MRD) for each sensor emerges. In turn, if the standard deviation, a representation of the variability at each sensor, is small relative to the scale of MRD values, one can conclude that a network is temporally stable. This analysis method is analogous to work performed in Cosh et al. $(2008 ; 2013)$.

\section{Linear Scaling Functions}

In this case, a simple linear regression is generated to relate the values of the single, permanent, USCRN gauges to the weighted average of sensors in the temporary networks 
that form either the $3-\mathrm{km}$ or $9-\mathrm{km}$ estimated average. This structure of these relationships is shown in Equations 1 and 2, below:

$\theta_{\text {ave }}=\beta_{1} \theta_{U S C R N}+\beta_{0}$

(Equation 1)

$\theta_{\text {ave }}=\sum_{i=1}^{n} \omega_{i} \theta_{i}$

(Equation 2)

In the above equations, $\omega_{i}$ denotes the weight associated with a given temporary network sensor's soil moisture value, $\theta_{i}$. The sum of all values of $\omega_{i}$ is unity. This yields the weighted average, $\theta_{\text {ave }}$, which represents the average soil moisture over the $3-\mathrm{km}$ or $9-\mathrm{km}$ pixel in which we are interested in assessing temporal and spatial stability. $\theta_{\text {USCRN }}$ signifies the soil moisture value from the permanent station, which is in turn, scaled via a slope, $\beta_{1}$, and an intercept, $\beta_{0}$. The values of these parameters are calibrated using a randomly-selected $80 \%$ of the soil moisture data set and validated on the $20 \%$ that remain.

\section{Sub-network Analysis}

Utilizing this approach, a temporary network average consisting of n-sensors is compared with various sub-networks containing $\mathrm{n}-1$ sensors, then $\mathrm{n}-2$ sensors, etc. Considering an average of a temporary network with $\mathrm{n}$ sensors, the number of combinations of $\mathrm{r}$ sensors (for $\mathrm{r}<\mathrm{n}$ ) is given in Equation 3:

$\left(\begin{array}{l}n \\ r\end{array}\right)=\frac{n !}{(n-r) ! * r !}$

(Equation 3)

If $\left(\begin{array}{l}n \\ r\end{array}\right)<1000$, all such combinations are evaluated, and for each an RMSE value is calculated between the sub-network and the full temporary network. The average RMSE 
represents the error between a sub-network of size $r$, and the complete temporary network.

If $\left(\begin{array}{l}n \\ r\end{array}\right)>1000$, for computational expediency, a randomly selected set of 1000 combinations of size $r$ are chosen and the reported RMSE is the average thereof. This analysis is performed for $\mathrm{r}=1$ through $\mathrm{r}=\mathrm{n}-1$, allowing a determination of how many sensors can be removed from a temporary network without substantial degradation of performance.

\section{Variability vs. Wetness}

Intuition might suggest that the variability across a network of temporary sensors would be largest during periods of wetting and drying. After a prolonged period without rain, all proximally-located sensors should stabilize at a low level at or near the residual soil moisture contents of the area in question. Similarly, after substantial precipitation events, all sensors should approach their levels of saturation. It is within the intermediate soil moisture levels where one might expect to observe the greatest variability across the temporary network. To this end, analysis is performed comparing the standard deviations of all reporting sensors within the temporary network as a function of the average of same.

\section{Network variability vs. 3-Profile Variability}

By design, the USCRN soil moisture values reported at sites of permanent installations are the average of three co-located (separated by distances of several meters), but independent instrument measurements. Assessments of the random errors at USCRN installations via triple collocation are analyzed and discussed in greater detail in Coopersmith et al (2016, i). In this case, we investigate briefly whether the variability within the triad of USCRN measurements is related to the variability across the sensors comprising the temporary 
network. As there are only three USCRN profiles available (and the calculation of standard deviation is generally dubious for such small sample sizes), an RMSD calculation about the mean value of the three profiles is obtained in Equation 4.

$R M S D=\sqrt{\sum_{i=1}^{3}\left(\theta_{i}-\bar{\theta}\right)^{2}}$

In the above, $\theta_{i}$ denotes the soil moisture reading at one of the three USCRN profiles and $\bar{\theta}$ signifies the average of those three measured values. These RMSD values are, in turn, compared with the variability of the temporary network sensors at the $3-\mathrm{km}$ and $9-\mathrm{km}$ scales.

\section{Results}

The soil probes of the temporary network were calibrated initially to the soil type located at each individual location. The gravimetric measurements that occurred at each temporary station throughout the life of the temporary networks served as a set of quality measurements to calibrate the dielectric measurements. These calculations are applied across all stations uniformly which is not unreasonable for the Crossville site. The Millbrook site contained slightly more variation with respect to the soil textures, but the heterogeneity is not expected to influence the results of the analysis significantly. Calibrated values were used for evaluation of the spatial and temporal variability of soil moisture across the entire network. 


\section{Temporal Stability Analysis}

Figure 2 illustrates that despite the $0.2-0.3 \mathrm{~m}^{3} / \mathrm{m}^{3}$ range in soil moisture values observed, relative positioning of sensors is temporally stable to a large degree at the Millbrook site. The red line in Figure 2 also suggests that the USCRN sensor is, in general, likely to produce values that are drier than those reported by the temporary network at 9-km scale (blue line) or 3-km scale (green line). As the plots show, a great deal of variability occurs across the temporary networks at Millbrook site. However, despite this variability, temporal patterns of the average $9-\mathrm{km}$ and $3-\mathrm{km}$ soil moisture values replicate the wetting and drying cycles of the USCRN station. Average soil moisture values for the entire period of record confirm that the USCRN station was slightly drier (mean = $0.2066 /$ standard deviation $=0.0525)$ than the $9-\mathrm{km}($ mean $=0.2587 /$ standard deviation $=$ $0.0541)$ and $3-\mathrm{km}($ mean $=0.2364 /$ standard deviation $=0.0465)$ grids at Millbrook. 


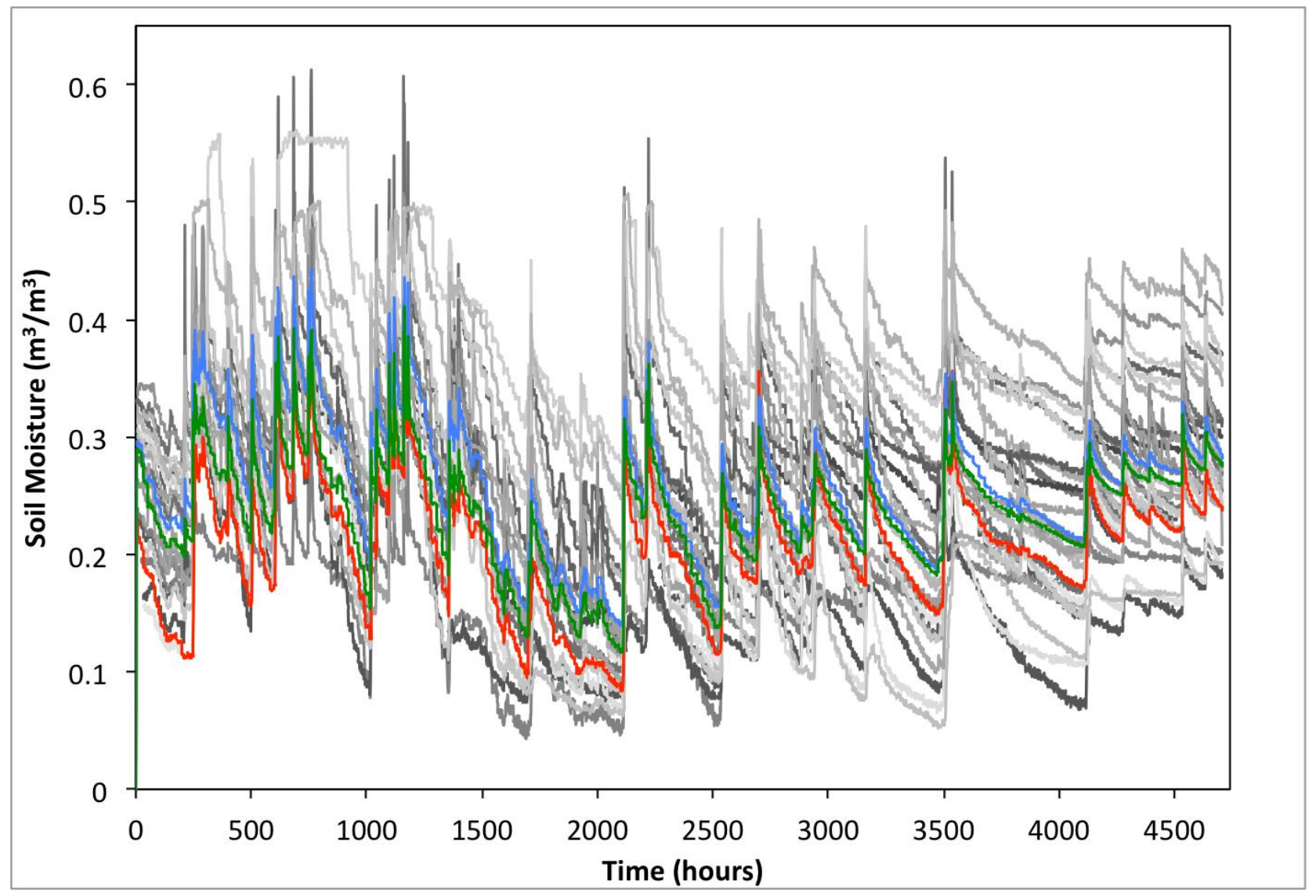

Figure 2. Mean soil moisture variability of the temporary network at Millbrook, NY.

The red line denotes the USCRN value, the blue line represents the 9-km average, and the green line signifies the 3-km average. The various shades of grey represent the individual probe values within the temporary network. 

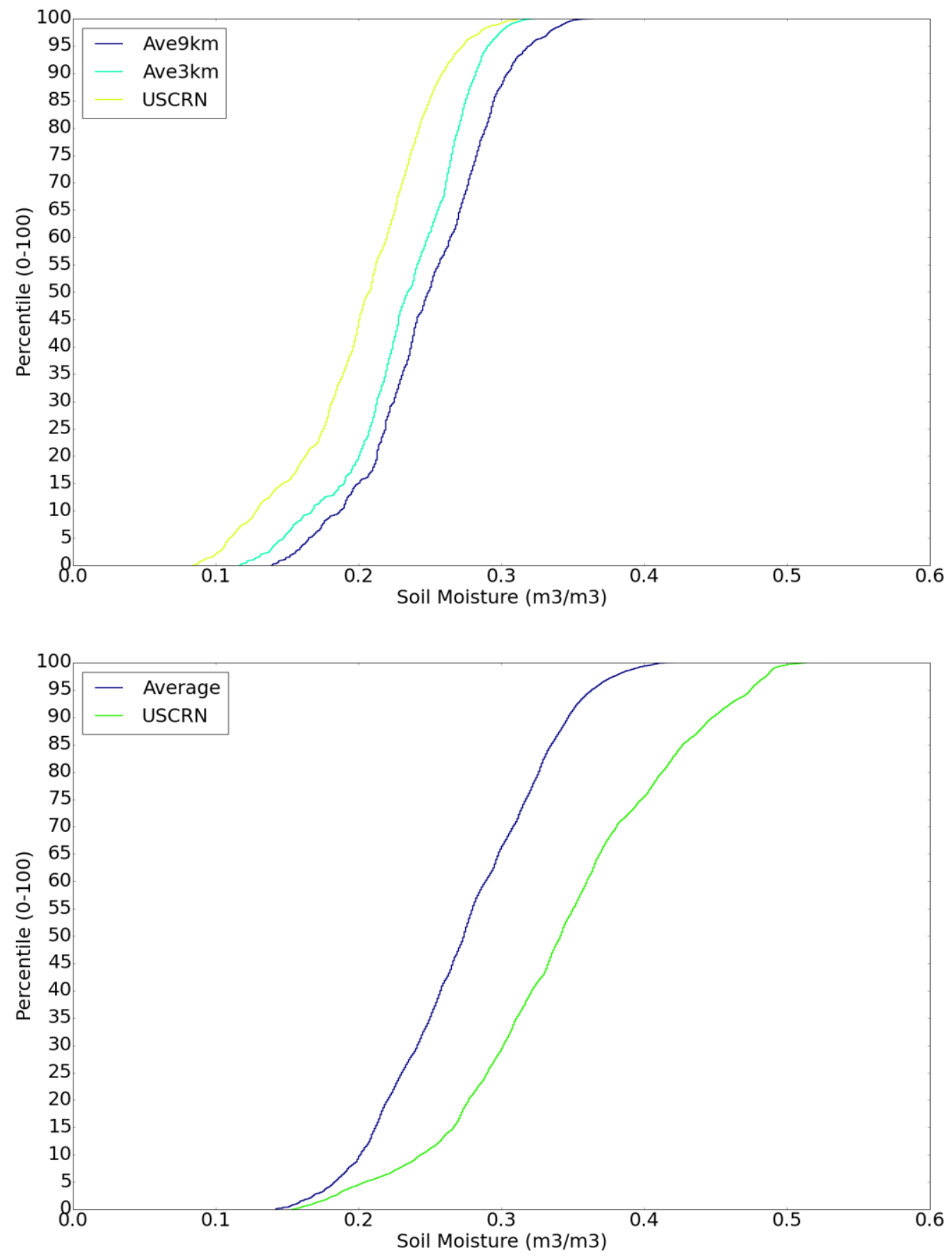

Figure 3. CDF plots for Millbrook (top, at 3-km and 9-km scales) and Crossville (bottom) USCRN gauges and temporary networks.

Cumulative distribution frequency plots were constructed to evaluate the population of USCRN values and compare them to 9-km and 3-km grid average value populations (Figure 3). The cumulative distribution frequency plots show that the three time series at 
Millbrook display similar patterns of soil moisture for the period of record. Again, as expected, USCRN values were consistently drier than the 9-km values. The $3-\mathrm{km}$ values were wetter than the USCRN values in the lower soil moisture percentages but were more similar to the USCRN values in the higher soil moisture conditions. In the lower panel, at Crossville, we observe that the USCRN gauge is considerably wetter than the distribution describing the surrounding temporary network. In contrast with the Millbrook site, the USCRN station at Crossville was more similar to the temporary network when drier - the values diverged as the conditions became wetter. 

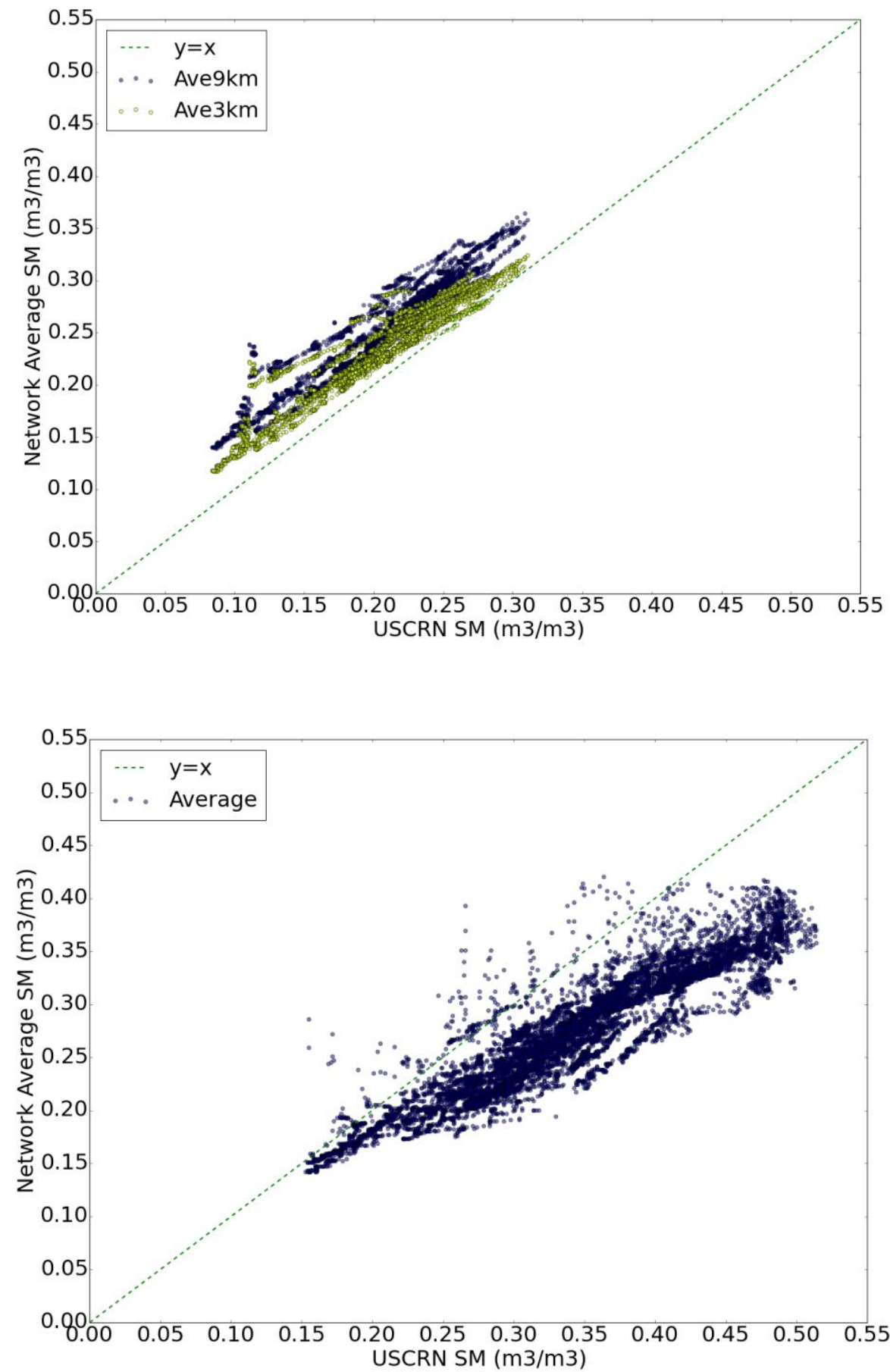

Figure 4. USCRN soil moisture vs. temporary network average at $3 \mathrm{~km}$ (green dots) and $9 \mathrm{~km}$ (blue dots) scales at Millbrook (top) and USCRN vs. temporary network at Crossville (bottom).

Correlations between the USCRN values and the Millbrook temporary network's 3-km and 9-km products yield strong relationships (Figure 4, top panel). The 3-km temporary 
network grid had a higher correlation $\left(r^{2}=0.90\right)$ than the $9-\mathrm{km}$ grid $\left(\mathrm{r}^{2}=0.84\right)$. As would be expected, the correlation between the 3-km vs. 9-km grids was even higher $\left(r^{2}=0.94\right)$. In Crossville (Figure 4, bottom panel), the correlation between the USCRN and temporary network average is comparable, at $r^{2}=0.85$, but demonstrates considerable non-linearity at volumetric soil moisture amounts above $0.3 \mathrm{~m}^{3} / \mathrm{m}^{3}$ (a value rarely exceeded at Millbrook).

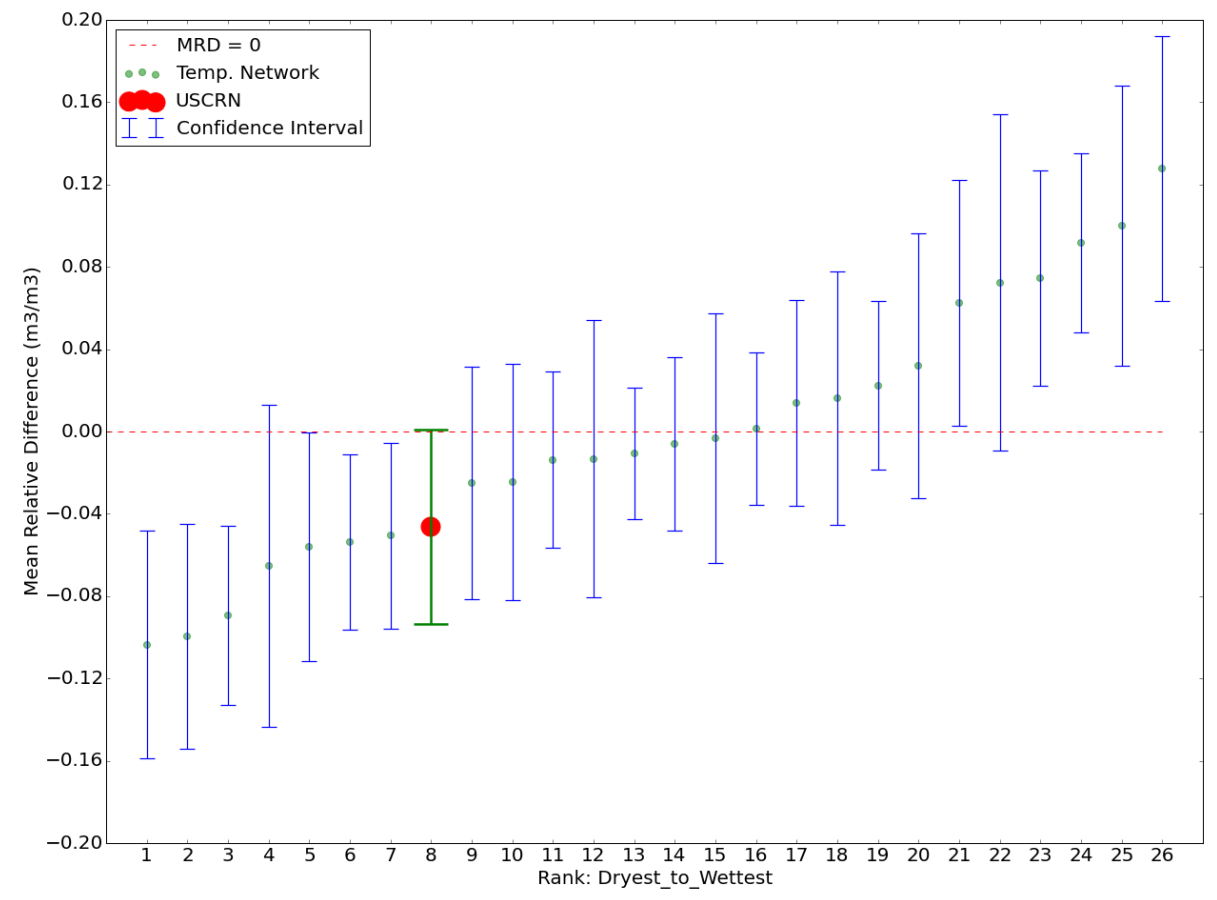




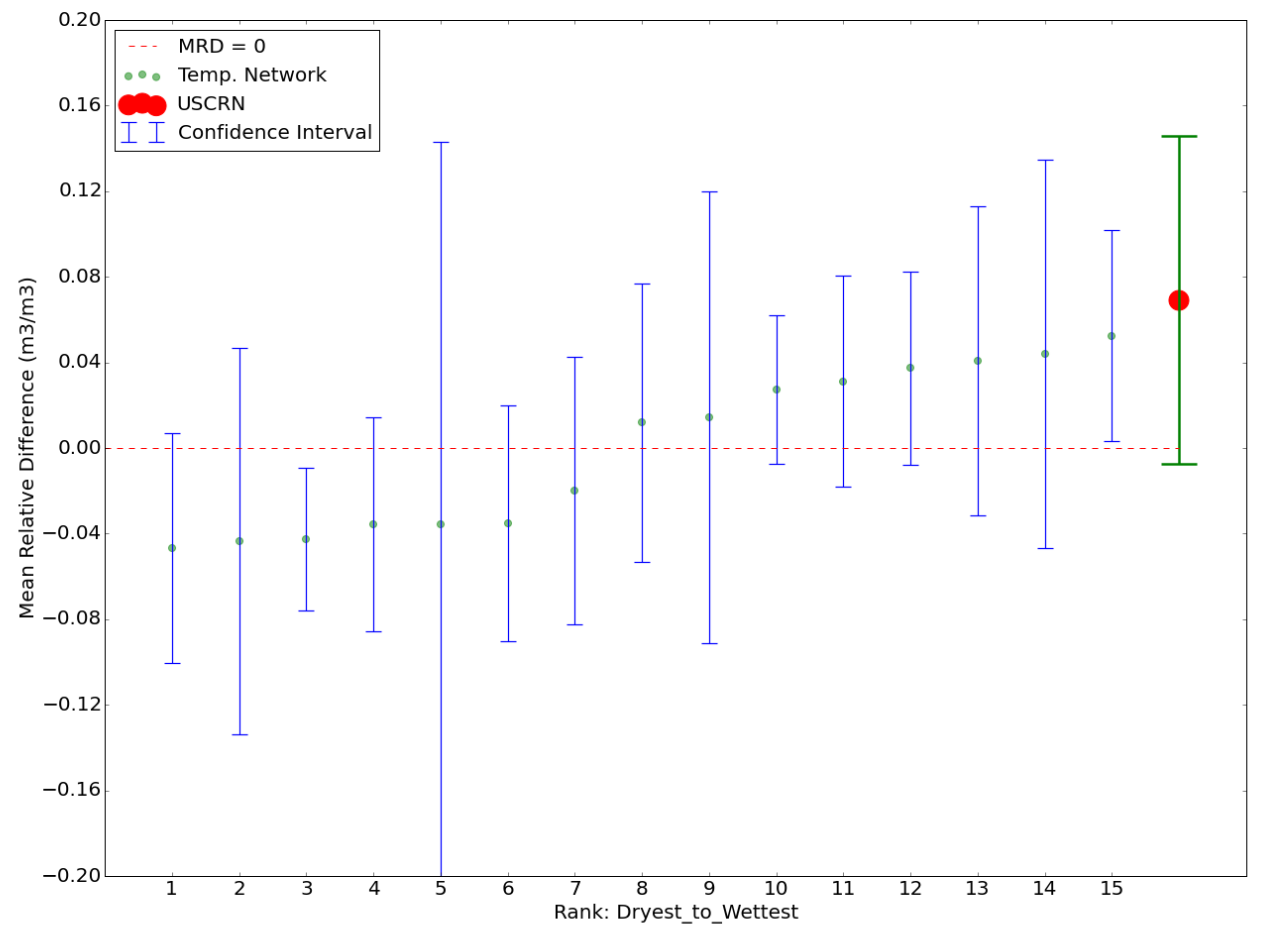

Figure 5. Mean relative difference plot of the Millbrook (top) and Crossville (bottom) temporary networks. Error bars represent the standard deviations of the relative differences for each station with the remaining stations.

Figure 5 provides a summary of the temporal stability of the temporary networks. With mean-relative-difference (MRD) values at Millbrook spanning a range of over $0.2 \mathrm{~m}^{3} / \mathrm{m}^{3}$, while the standard deviation of readings at each sensor tend to hover near $0.05 \mathrm{~m}^{3} / \mathrm{m}^{3}$, the top panel of Figure 5 confirms what Figure 2 suggests - wetter and drier sensors tend to remain so. In contrast to some extent, at the Crossville location, the range of MRD values falls below $0.10 \mathrm{~m}^{3} / \mathrm{m}^{3}$ while the standard deviations are often above $0.10 \mathrm{~m}^{3} / \mathrm{m}^{3}$. In some cases, standard deviations are considerably larger than the MRD range displayed by the temporary network. For this reason, fewer sensors seem consistently wetter or drier. Additionally, these paired images illustrate that, within the Millbrook network, the USCRN gauge has been installed in a location that is slightly drier than its surroundings, 
whereas in Crossville, the installation site is substantially wetter than the peripheral landscape.

\section{Linear Scaling Functions}

For the Millbrook location, time series data displayed in Figure 6 show the adjustment of the USCRN soil moisture (red series) to a scaled average (blue series) via an optimal gain and offset derived using Equation 1. The top panel represents the scaling for the 3-km grid and the bottom panel represents the scaling for the $9-\mathrm{km}$ grid. For the purposes of data reliability, all time series values while rain is falling and during the four hours immediately thereafter were removed from the regression analysis. Rain requires some non-zero quantity of time to infiltrate to the depth of the sensor and short-term sensor flooding is also possible. A four-hour removal of this nature, used for calibration of USCRN sensors in Coopersmith et al, 2015(a) and Coopersmith et al, 2015(b) resolves this issue.

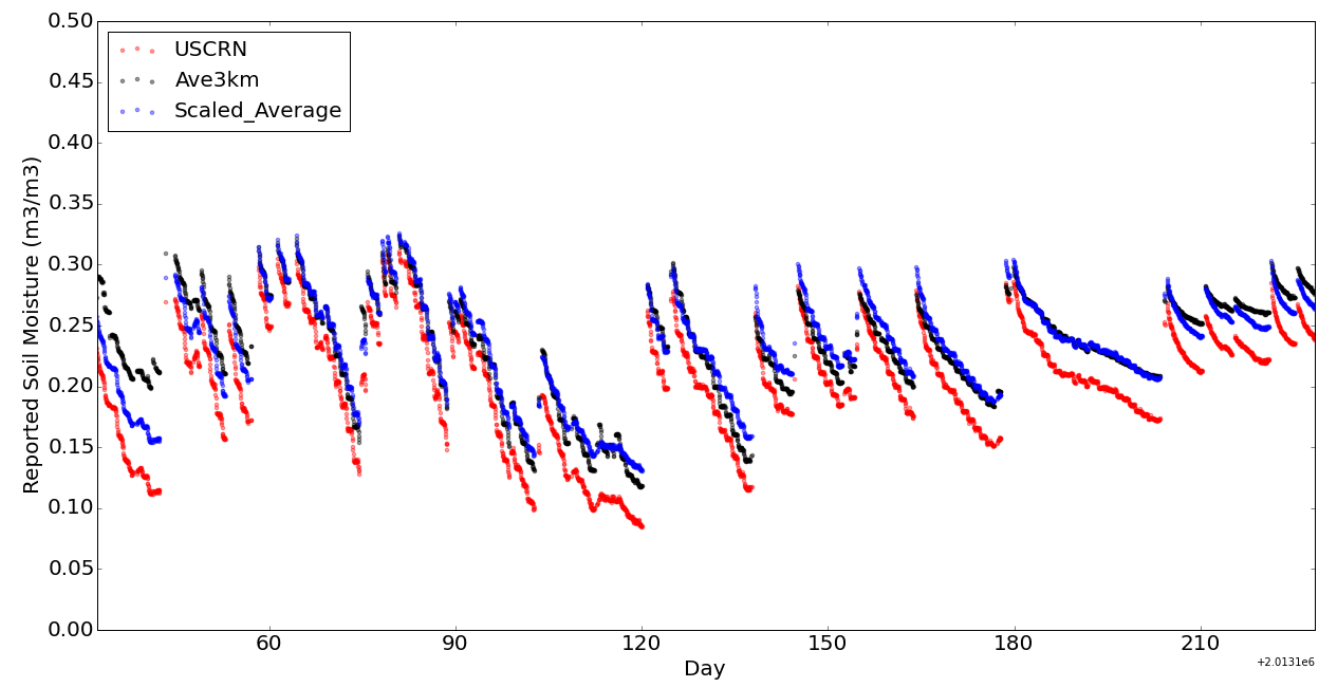




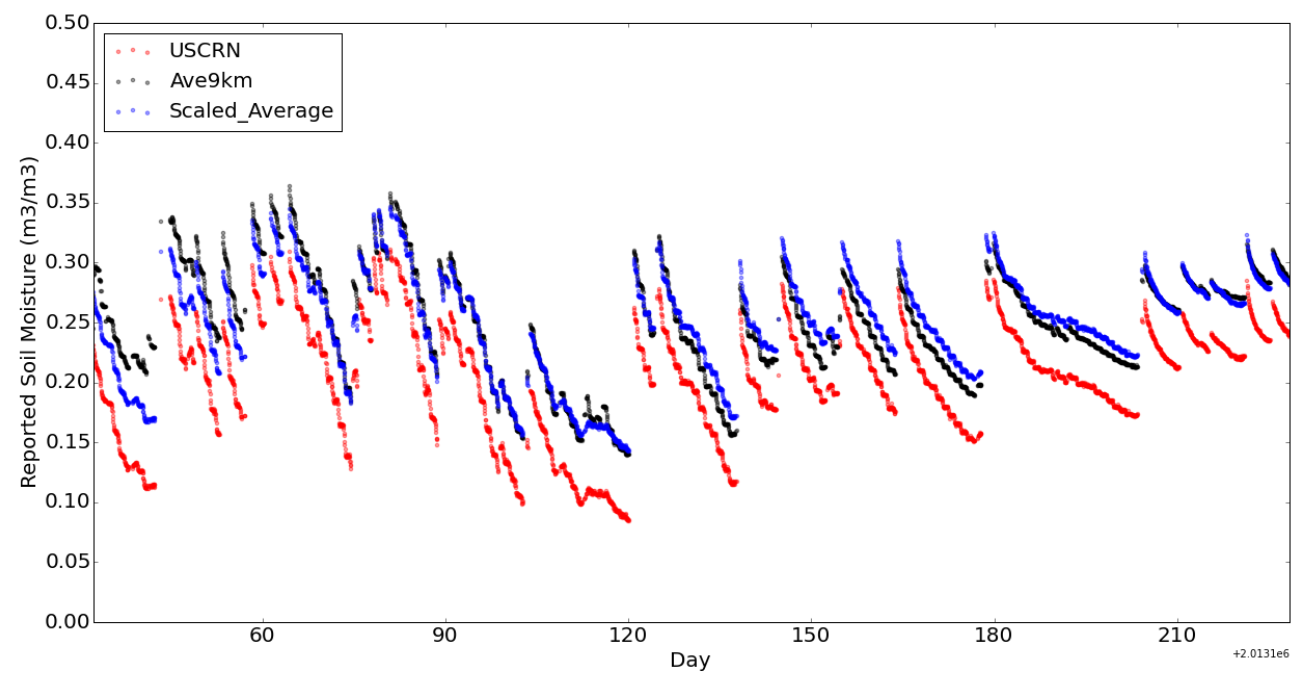

Figure 6. Gain and offset adjustments of USCRN values to approximate the average of the Millbrook temporary network at the $3 \mathrm{~km}$ (top) and $9 \mathrm{~km}$ (bottom) scales.

The correlations between the Millbrook USCRN values and the temporary network 3-km and $9-\mathrm{km}$ averages are strong $\left(\mathrm{r}^{2}=0.90\right.$ and 0.89 respectively). These values are obtained, as discussed in the methodology section by random selection of $80 \%$ of the time series data. Validating on the remaining $20 \%$ yields comparable values $\left(r^{2}=0.89\right.$ and 0.90 respectively). RMSE values prior to the introduction of optimal gains and offsets were 0.033 and $0.049 \mathrm{~m}^{3} / \mathrm{m}^{3}$ at $3-\mathrm{km}$ and $9-\mathrm{km}$ scales, respectively. After the introduction of these adjustments, RMSE values fall to 0.013 and $0.015 \mathrm{~m}^{3} / \mathrm{m}^{3}$ during calibration for the 3-km and 9-km average respectively and $0.014 \mathrm{~m}^{3} / \mathrm{m}^{3}$ during validation.

Within Crossville, an analogous analysis is performed and presented in Figure 7. The correlation between the USCRN values and the temporary network average are strong in calibration $\left(r^{2}=0.86\right)$ and validation $\left(r^{2}=0.85\right)$, though perhaps not as high as those observed in Millbrook. The RMSE value prior to the introduction of an optimal gain and offset is $0.076 \mathrm{~m} 3 / \mathrm{m} 3$, which falls to $0.021 \mathrm{~m} 3 / \mathrm{m} 3$ (calibration) once an optimal linear 
correction is implemented and is only marginally worse $(0.021 \mathrm{~m} 3 / \mathrm{m} 3)$ during validation. These results suggest that a single point of observation can effectively approximate the behavior of a small area network through calibration, even if the site location is not in the ideal position to represent the central tendency of the area soil moisture distribution.

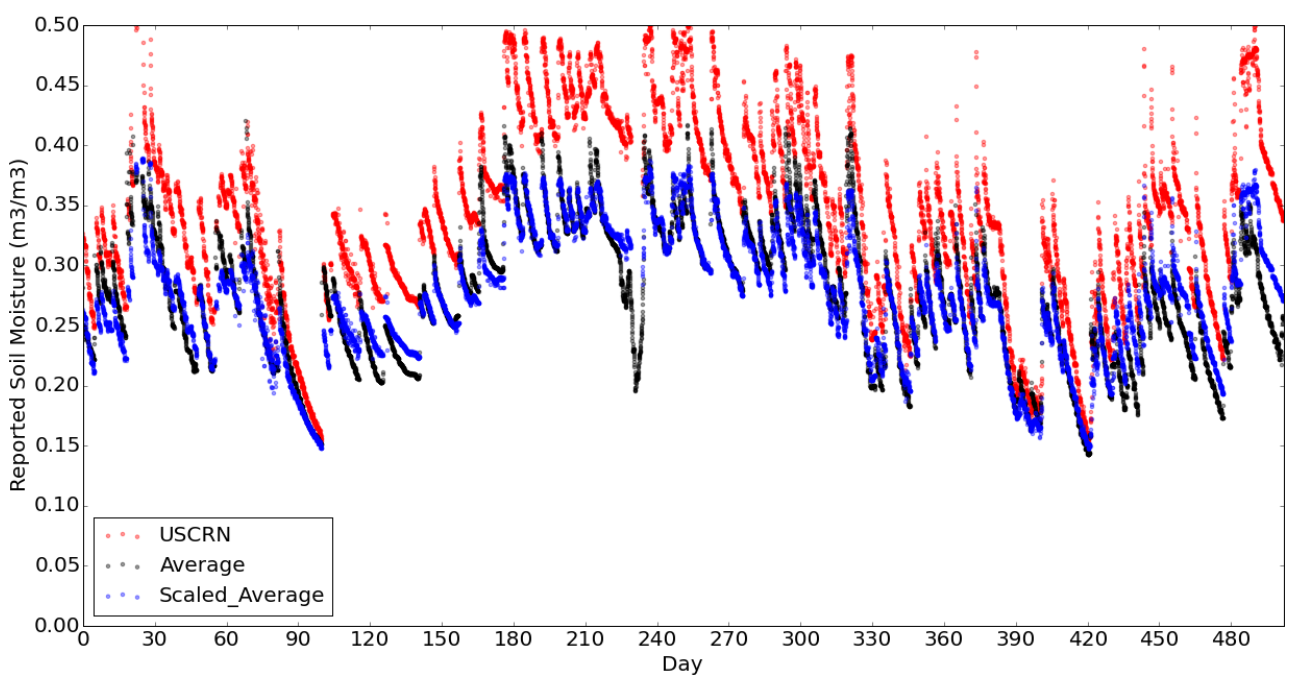

Figure 7. Gain and offset adjustments of the USCRN gauge values to approximate the average of the Crossville temporary network.

\section{Sub-network Analysis}

As temporary networks are still resource intensive, a sub-network analysis will help determine the number of sensors needed to achieve results that would appear comparable to that of the complete network. Figure 8 presents the RMSE between the various combinations of sub-networks as compared to the 3-km (top) and 9-km (bottom) products, respectively. In both panels, a green, dotted-line presents the approximate random error associated with a hydraprobe measurement at this depth, as determined by the triplecollocation analysis performed in Coopersmith et al $(2016, \mathrm{i})$. The confidence intervals are determined as the standard deviation of all combinations of the size listed on the $\mathrm{x}$-axis 
chosen from the complete network of size 15 (3-km product) or 25 (9-km product). Where the number of such combinations is computationally-cumbersome, 1,000 random combinations are selected and used to generate the confidence intervals illustrated.

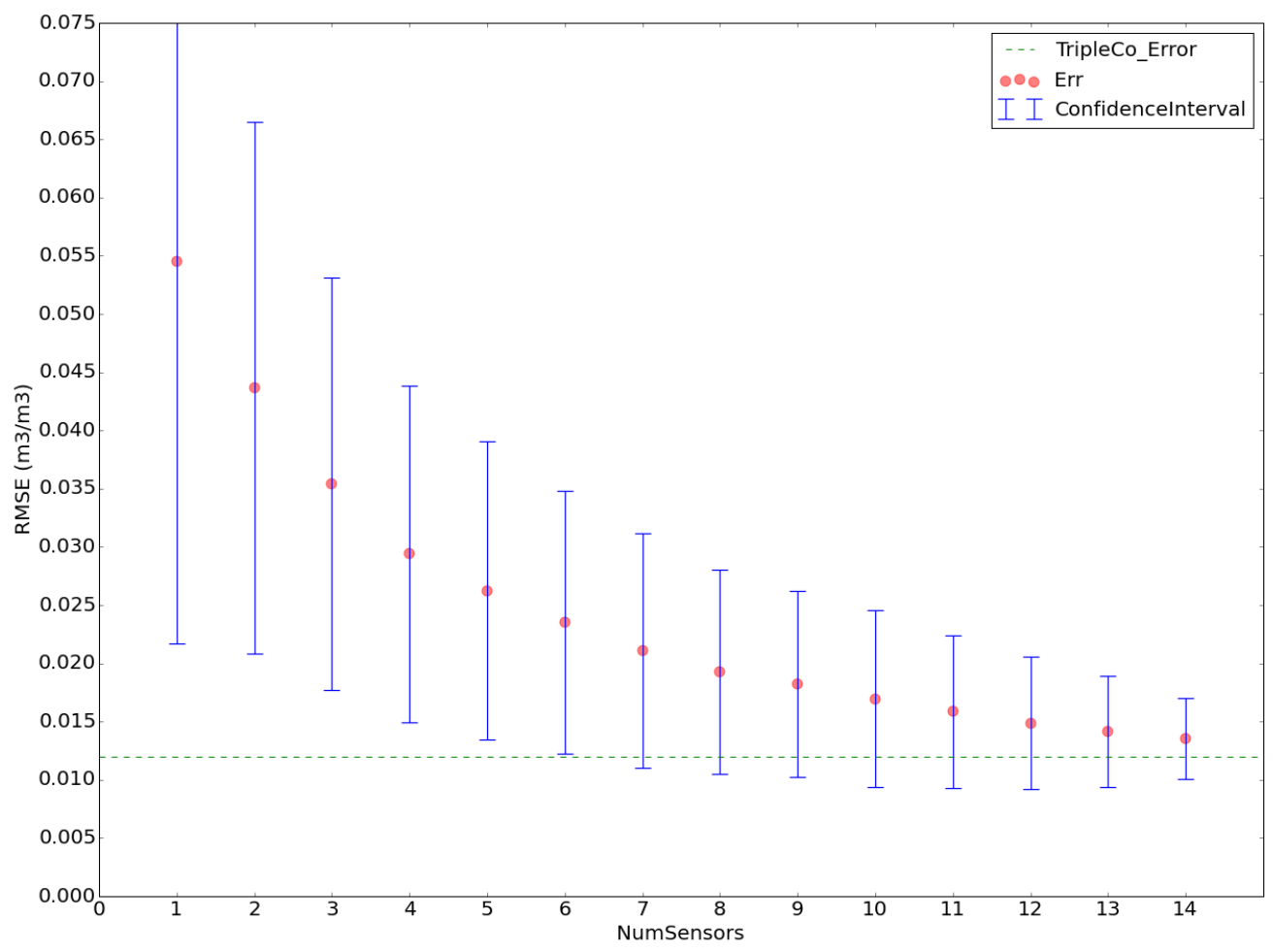




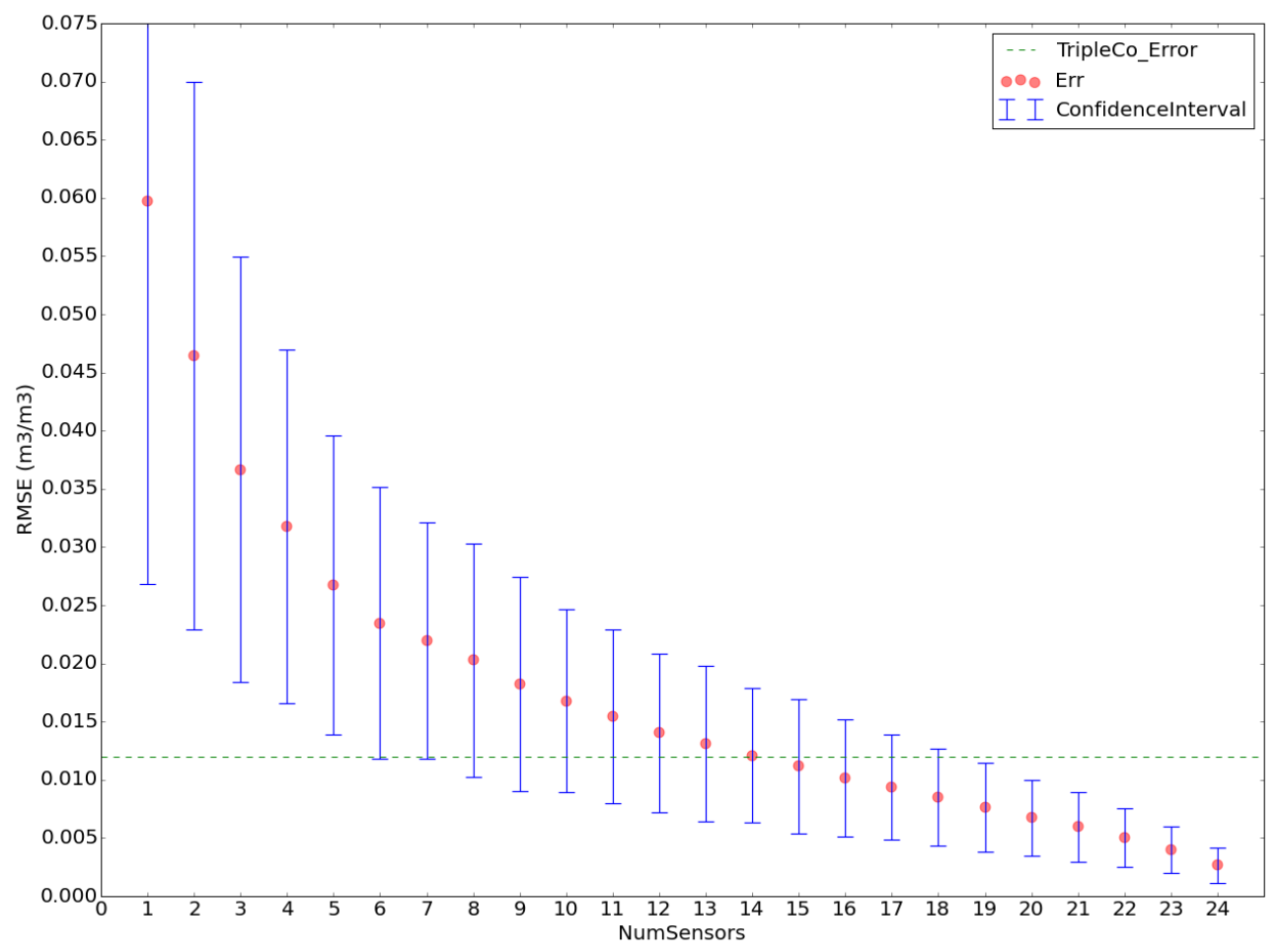

Figure 8. RMSE between complete Millbrook temporary network and combinations of lesser numbers of sensors at 3-km (top) and 9-km (bottom) scales.

At both 3-km and 9-km scales, we observe that even without the full contingent of sensors, RMSE values against the complete temporary network average that fall below the inherent random error in hydraprobe measurements are attainable. As the presented confidence intervals illustrate a range of one standard deviation above or below the mean, the probability of a random combination of sensors of size $r$ (see Equation 3) presenting an RMSE below the upper-end of the confidence interval is $\sim 84 \%$. This suggests, that if, of the 25 sensors comprising the 9-km average, 14 are installed, the expected value of the RMSE would be roughly the value of random measurement error. If 19 are available, we would expect that RMSE to be below the random measurement error with $84 \%$ confidence. At the 3-km scale, errors are slightly larger, as we are removing sensors 
from a group of 15 rather than 25 . We observe that the expected RMSE value asymptotically approaches the random error associated with a hydroprobe measurement. Figure 9 presents the analogous plot at the Crossville location.

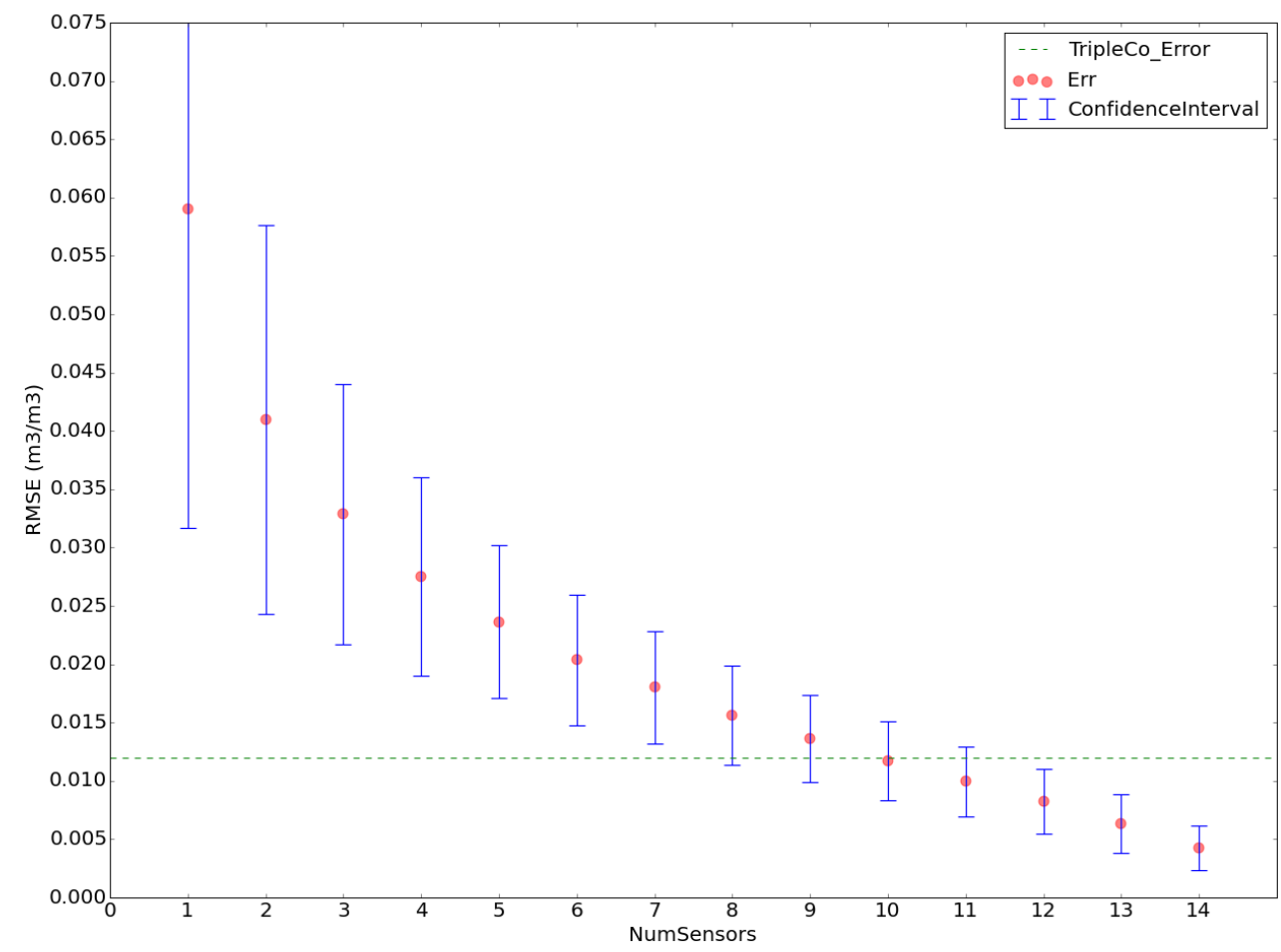

Figure 9. RMSE between complete Crossville temporary network and combinations of lesser numbers of sensors.

These results suggest that even fewer sensors (of a 15-sensor temporary network) will be required to achieve errors below the level of random measurement error, in this case only 10 will lead to expected RMSE values below the random error level and 12 sensors will achieve this standard with $84 \%$ confidence.

\section{Variability vs. Wetness}

The average standard deviation among the temporary network's constituent sensors as a function of the average soil moisture values reported by those sensors was calculated at 
3-km and 9-km scales at Millbrook, and 3-km scale at Crossville. At Millbrook, it is evident at the 3-km scale (Figure 10) that soil moisture variability across the temporary network is largest during intermediate conditions, tapering off at both the upper and lower ends of the distribution when all sensors are fully dried or fully saturated. However, at the 9-km scale, the same relationship is no longer observed. In this case, the variability across the temporary network may be the result of unevenly received precipitation events in addition to topographic, vegetative, or edaphic variability. The network at Crossville also shows no systematic relationship between variability and wetness, even at the 3-km scale (not shown). Possibly, this may result from wet conditions at the Crossville site - considerable rainfall arrived while the temporary stations were installed.

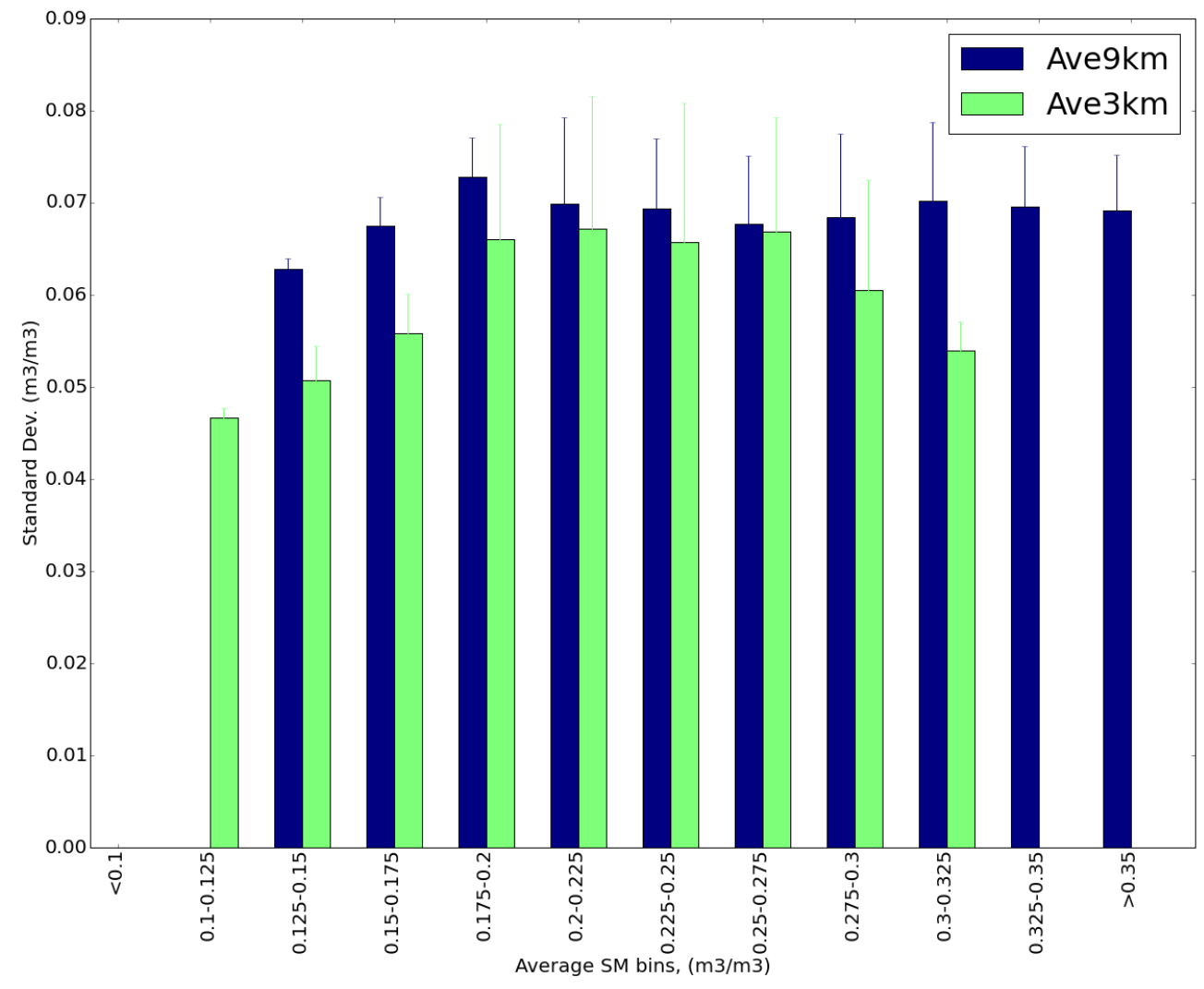




\section{Figure 10. Standard deviation of Millbrook temporary network sensors vs. average soil moisture}

\section{Variability vs. 3-Profile Variability}

Taking advantage of the USCRN's unique acquisition of three soil moisture profiles, it would be interesting to see if the near-point variability relates in any way to the 3-km or 9$\mathrm{km}$ scale spatial variability around the site. Figure 11 presents the variability of the temporary network at Millbrook as a function of the variability observed in the three profiles of the USCRN installation (Equation 4). At neither the 3-km, nor the 9-km scale does the variability of the network seem dependent upon the consistency of the threeprofile measurements at the single, permanent gauge. Though the 3-km scale does seem to present slightly less variability at the drier end of its distribution, the overall results seem to suggest that the variability in terms of precipitation, topography, soil texture, and vegetation cover all explain the temporary network's variability rather than specific conditions that manifest themselves as differences in the three profile measurements. Crossville displayed a similar lack of a relationship (not shown). 


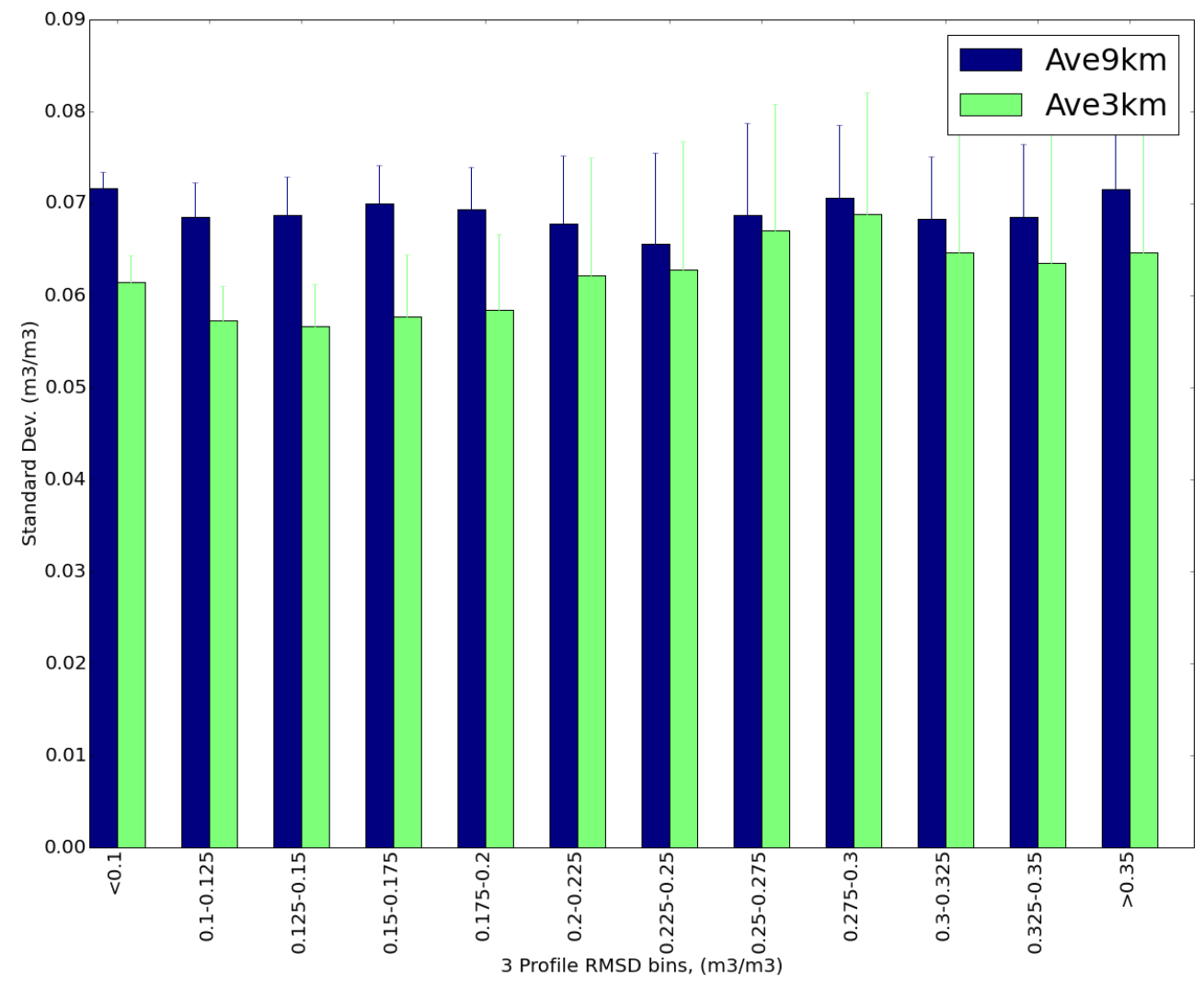

Figure 11. Standard deviation of temporary network sensors at Millbrook vs. threeprofile variability of the USCRN station.

\section{Discussion}

Previous research has demonstrated that a dense network of sensors can be deployed to produce estimates at the $500 \mathrm{~m}$ resolution by leveraging a combination of in situ sensory resources, and if needed, knowledge of topographic and edaphic features (Coopersmith et al., 2015, iii). By matching smaller 500m x 500m squares with models calibrated at sensors located in similarly textured soils of similar topographic features, accurate estimates within each square are possible. Essentially, this methodology enables the creation of estimates in every $500 \mathrm{~m} \times 500 \mathrm{~m}$ square within a larger $(\sim 40 \mathrm{~km} \times \sim 40 \mathrm{~km}$ in the article referenced above), then subsequently upscaling those estimates to $3 \mathrm{~km}, 9 \mathrm{~km}$, or $36 \mathrm{~km}$ (the scales employed by the SMAP satellite mission) by aggregating and averaging the constituent 
$500 \mathrm{~m} \times 500 \mathrm{~m}$ boxes. This facilitates more direct validation of satellite estimates (Coopersmith et al., 2015, iii).

The findings in this analysis suggest that errors decrease to the levels of random errors inherent in in situ sensor measurement (Coopersmith et al, 2016, i) with a network of approximately one-dozen sensors. As many dense permanent and temporary networks contain more than this quantity of sensory resources, these findings suggest upscaling can occur using even few sensors than are typically installed in dense networks. The number of sensors is likely to be even fewer if care is taken to ensure the chosen sensor locations represent the diversity of textures and topographies present within the test area. These upscaled estimates can be compared, in turn, with remotely-sensed estimates from satellites. In addition to comparisons with remote sensing, these upscaled estimates can be deployed within various dense networks (or sparse networks with lower resolutions than the aforementioned 500km) as a means of assessing drought. Given this analysis's findings of stable relationships for wetter and drier sensors within a given network, characterization of potential drought risks could be informed by knowledge of which sensors tend to be atypically wet or dry.

Previous research suggests that these findings are applicable in other locations and within different hydroclimates and soil textures (Coopersmith et al, 2015, i). The models calibrated during that analysis at both USCRN and the Soil Climate Analysis Network (SCAN; Schaefer et al, 2007) sites, produced low RMSE values in over 40 states throughout the continental USA. With respect to temporal stability, preliminary analyses in the Agricultural Research Service test watersheds (located in Arizona, Oklahoma, Idaho, 
Georgia, Iowa, and Indiana) suggest similar performance as sensors are removed can be achieved (Coopersmith and Cosh, 2016, ii, in-progress).

\section{Conclusions}

The results of this pilot study indicate that it is possible to accurately represent the spatial and temporal variability of a larger domain with an individual station with considerable accuracy, once a scaling relationship has been developed. Deploying a temporary network around a permanent station provides an estimate of the soil moisture characteristics for that location and these results suggest that approximately one dozen sensors distributed around a site for an entire seasonal cycle is likely to be sufficient to characterize the variability of the domain average. The accuracy of the USCRN, once scaled to the surrounding 3-km or 9-km average demonstrated RMSE values below 0.015 $\mathrm{m}^{3}$ during both calibration and validation. Temporal stability analysis reveals that wetter and drier sensors within the domain are robust in terms of their mean relative differences. Finally, while wetter and drier conditions do affect network variability (at least at the $3 \mathrm{~km}$ scale), the variability of the USCRN's three co-located profiles do not. This work describes a successful approach for using a sparse data network station for validation of a satellite remote sensing product.

Additional work is needed to characterize the differences seen at other locations with varying soil conditions and landcover type. The study at Millbrook demonstrates that the analytic approaches presented in this paper are useful even with a target area that has substantial soil moisture variability due to a heterogeneous landscape. The study at Crossville shows that even a primary station located in a less representative soil moisture 
environment can still be successfully related to the variations in soil moisture for the surrounding area. A similar study at a location with a less heterogeneous landscape or more consistent soil type would likely produce even less variability and a more accurate representation of the local area with a properly calibrated single point observation. The utility of in situ soil moisture measurements at point locations in sparse networks can be increased substantially through the use of temporary networks for area calibration.

\section{Acknowledgements}

This work was supported by NOAA through the Cooperative Institute for Climate and Satellites - North Carolina under Cooperative Agreement NA09NES4400006. This work was also supported by the NASA Terrestrial Hydrology Program (NNH10ZDA001NTHP) and USDA Agricultural Research Service. USDA is an equal opportunity provider and employer. Additional thanks are owed to Howard Diamond and NOAA's Atmospheric Turbulence and Diffusion Division (ATDD).

\section{References}

Beck, L. R. Lobitz, B. M., Wood, B. L., 2000, Remote sensing and human health: new sensors and new opportunities, Emerging Infectious Diseases, 6(3):217-227.

Bell, J.B., Palecki, M. A., Baker, C. B., Collins, W. G., Lawrimore, J. H., Leeper, R. D., Hall, M. E., Kochendorfer, J., Meyers, T. P., Wilson, T., and Diamond, H. J., 2013: U.S. Climate Reference Network Soil Moisture and Temperature Observations. J. Hydrometeor, 14, 977-988. doi: http://dx.doi.org/10.1175/JHM-D-12-0146.1

Bell, J.E., Leeper, R.D., Palecki, M.A., Coopersmith, E.J., Wilson, T., Bilotta, R., Embler, S. Evaluation of the 2012 drought with a newly established national soil monitoring network. 2015. Vadose Zone Journal. doi:10.2136/vzj2015.02.0023

Blunden, J., and Arndt, D. S., 2013, State of the Climate in 2012, Bull. Amer. Meteor. Soc., 94(8), S1-S238.

Chan, S., Bindlish, R., O’Neill, Peggy .E., Njoku, Eni., Jackson, T.J., Colliander, Andreas, Chen, F., Burgin, M., Dunbar, R.S., Peipmeier, J, Yueh, S., Entekhabi, Dara, Cosh, M.H., Seyfried, M.S., Bosch, D.D., Starks, P., Goodrich, D.C., Prueger, J.H., Crow, W.T., Caldwell, T., Walker, J., Wu, X., Pacheco, A., McNairn, H., Anderson, M.C. 2016. Assessment of the SMAP Level 2 passive Soil Moisture Product IEEE Transactions on Geoscience and Remote Sensing, submitted. 
Coopersmith EJ, Cosh MH, Bell JE, Crow WT. Multi-profile analysis of soil moisture within the U.S. Climate Reference Network. (2016, i). Vadose Zone Journal. doi:10.2136/vzj2015.01.0016

Coopersmith EJ, Cosh MH. Understanding temporal stability: A long-term analysis of ARS watersheds in the $21^{\text {st }}$ century $(2016$, ii). In-progress.

Coopersmith EJ, Bell JE, Cosh MH, Extending the soil moisture data record of the U.S. Climate Reference Network (USCRN) and Soil Climate Analysis Network (SCAN). (2015, i). doi:10.1016/j.advwatres.2015.02.006

Coopersmith EJ, Cosh MH, Bindlish R, Bell JE. Comparing AMSR-E soil moisture estimates to the extended record of the U.S. Climate Reference Network (USCRN). (2015, ii). Advances in Water Resources. doi:10.1016/j.advwatres.2015.09.003

Coopersmith, EJ, Cosh MH, Petersen, WA, Prueger, J, Niemeier JJ. Soil moisture model calibration and validation, an ARS Watershed on the South Fork Iowa River. (2015, iii). Journal of Hydrometeorology. doi: http://dx.doi.org/10.1175/JHM-D-14-0145.1

Cosh, M.H., Jackson, T.J., Smith, Craig, Toth, Brenda, Berg, A. 2013. Validating the BERMS in situ soil water content data record with a large scale temporary network, Vadose Zone Journal, 12, 2, doi: 10.2136/vzj2012.0151.

Cosh, M. H., Jackson, T. J., Moran, M.S., and Bindlish, R. Temporal persistence and stability of surface soil moisture in a semi-arid watershed. Remote Sens. Environ. 112 (2): 304-313. 2008

Cosh, M. H., Starks, P., Guzman, J., Moriasi, D., 2013, Long-term agro-hydrological research in upper Washita River experimental watersheds: Inter-annual persistence of soil water content profiles, Journal of Environmental Quality, 43, 1328-1333, doi: 10.2134/jeq2013.08.03

Crow, W. T., Berg, A., Cosh, M. H., Loew, A., Mohanty, B., Panciera, R., de Rosnay, P., Ryu, D., and Walker, J., 2012, Upscaling sparse ground-based soil moisture observations for the validation of satellite surface soil moisture products. Rev. Geophys., 50, RG2002, doi:10.1029/2011RG000372.

Diamond, H. J., Karl, T. R., Palecki, M. A., Baker, C. B., Bell, J. E., Leeper, R. D., Easterling, D. R., Lawrimore, J. H., Meyers, T. P., Helfert, M. R., Goodge, G., and Thorne, P. W., 2013: U.S. Climate Reference Network after One Decade of Operations: Status and Assessment. Bull. Amer. Meteor. Soc., 94, 485-498. doi: http://dx.doi.org/10.1175/BAMS-D-12-00170.1

Dirmeyer, P., J. Wu, H. Norton, W. Dorigo, S. Quiring, T. Ford, J. Santanello, M. Bosilovich, M. Ek, R. Koster, G. Balsamo, and D. Lawrence, 2016: Confronting weather and climate models with observational data from soil moisture networks over the United States. J. Hydrometeor. doi:10.1175/JHM-D-15-0196.1, in press. 
Dorigo, W., W. Wagner, R. Hohensinn, S. Hahn, C. Paulik, A. Xaver, A. Gruber, M. Drusch, S. Mecklenburg, and P. Van Oevelen, 2011: The International Soil Moisture Network: a data hosting facility for global in situ soil moisture measurements, Hydrol. Earth Syst. Sci., 15, 1675-1698.

Dorigo, W.A., A. Xaver, M. Vreugdenhil, A. Gruber, A. Hegyiová, A.D. Sanchis-Dufau, D. Zamojski, C. Cordes, W. Wagner, and M. Drusch, 2013: Global automated quality control of in situ soil moisture data from the International Soil Moisture Network. Vadose Zone Journal, 12, doi:10.2136/vzj2012.0097.

Ford, T.W., and S. M. Quiring, 2014. Comparison and applications of multiple methods for the interpolation of soil moisture observations. Int. J. of Climatology, 34, 2604-2621, doi:10.1002/2014JD021490.

Kornelsen, K.C., M.H. Cosh, and P. Coulibaly, 2015, Potential of bias correction for 14 downscaling passive microwave and soil moisture data, J. Geophys. Res. Atmos., 120, 15 doi:10.1002/2015JD023550.

Ochsner, T. E., M. H. Cosh, R. H. Cuenca, W. A. Dorigo, C. S. Draper, Y. Hagimoto, Y. H. Kerr, K. M. Larson, E. G. Njoku, E. E. Small, and M. Zreda, 2013. State of the art in large-scale soil moisture monitoring. Soil Sci. Soc. Am. J., 77, 1888-1919, doi:10.2136/sssaj2013.03.0093.

Palecki, M. A., and J. E. Bell, 2013. U.S. Climate Reference Network soil moisture observations with triple redundancy: measurement variability. Vadose Zone Journal, 12, doi:10.2136/vzj2012.0158.

Quiring, S., T. Ford, J. Wang, A. Khong, E. Harris, T. Lindgren, D. Goldberg, and Z. Li, 2016: The North American Soil Moisture Database: Development and Applications. Bull. Amer. Meteor. Soc. doi:10.1175/BAMS-D-13-00263.1, in press.

Scaini, A., N. Sanchez, S. M. Vincente-Serrano, and J. Martinez-Fernandez, 2015. SMOS-derived soil moisture anomalies and drought indices: a comparative analysis using in situ measurements. Hydrol. Process. 29, 373-383, doi:10.1002/hyp.10150.

Schaefer, G., Cosh, M. H., and Jackson, T. J. The USDA Natural Resources Conservation Service Soil Analysis Network (SCAN). J. Atmos. Ocean. Tech. 24 (12): 2073-2077. 2007.

Stacy, P. K. R., Comrie, A. C., Yool, S. R., 2012, Modeling Valley Fever incidence in Arizona using a satellite-derived soil moisture proxy, GIScience \& Remote Sensing, 49(2):299-316.

Temimi, M., Lakhankar, T., Zhan, X., Cosh, M., Krakauer, N., Fares, A., Kelly, V., Khanbilvardi, R., Kumissi, L. Soil moisture retrieval using ground-based L-band passive microwave observations in Northeastern USA. (2014). Vadose Zone Journal. doi:10.2136/vzj2013.06.0101 
Vachaud, G.; Passerat De Silans, A.; Balabanis, P.; Vauclin, M., 1985, Temporal Stability of Spatially Measured Soil Water Probability Density Function, Soil Science Society of America Journal, 49(4):822-828 